Sädhanā, Vol. 18, Part 1, March 1993,pp. 105-124. () Printed in India.

\title{
New avenues in membrane science and technology
}

\author{
S S KULKARNI, M G KULKARNI and S NENE \\ National Chemical Laboratory, Pune 411008 , India \\ MS received 18 March 1991; revised 30 January 1992
}

\begin{abstract}
Recent advances and avenues for further research and development in three specific fields of membrane science and technology are reviewed. The potential of membrane processes for gas separation has been considerably improved by the development of new materials combining high permeability and selectivity. While working correlations between polymer structure and permeation characteristics have been evolved, there is need to further develop our basic understanding of this relationship. The second field reviewed is that of improving the separation characteristics of porous membrane filtration (ultra-/microfiltration). Recent promising approaches include the fabrication of membranes with uniform porosities, new module configurations and the manipulation of feed chemistries. The third area highlighted is that of hybrid membrane processes. These are considered both as integrated processes in which the membrane process operates in conjunction with another unit operation or as a coupled transport process in which the basic functioning of the membrane is intimately coupled with another physical or chemical process in single unit operation. The scope for basic research in these fields is indicated.
\end{abstract}

Keywords. Membrane; gas separation; ultrafiltration; microfiltration; hybrid membrane process.

\section{Introduction}

The use of membranes in various separation processes has increased enormously from its humble beginning as a laboratory curiosity to an estimated US $\$ 3$ billion world-wide market in 1990. Various membrane applications are also being practised in India. With a few exceptions, most of these are processes built around imported membrane technology such as ion selective membranes in chlor-alkali cells or reverse osmosis membranes for recycling refinery waste-water. Indigeneous membrane technology is also developing, e.g. the use of reverse-osmosis or electrodialysis membranes for brackish water purification and a few small applications using ultrafiltration or microfiltration membranes in pharmaceutical processing.

NCL Communication No. 5134 
The scope of membrane science and technology is much wider than that indicated by the few applications that are currently being practised in India. There have been new developments in membrane fabrication, processes and concepts. In this article we will focus on a few areas of membrane science and technology from the viewpoint of recent developments and opportunities. These areas are broadly as follows.

(1) Gas separation and pervaporation (permeation and evaporation) using membranes.

(2) Improved separations with porous membranes.

(3) Hybrid membrane processes.

\section{Gas separation by membranes}

Applications of membrane technology in gas separations are more recent as compared to other membrane processes such as reverse osmosis and microfiltration. The technology today competes with conventional gas-separation technologies such as cryogenics, adsorption and absorption processes, and the market for it is expected to grow rapidly in the years to come relative to other separation technologies. The market today is estimated to be $\$ 24$ million; according to an estimate, it is expected to grow to $\$ 268$ million in the next five years and thus exceed the market size for reverse osmosis (Business Technology Report 1986). It is therefore not surprising that a number of companies engaged in conventional gas-separation technologies such as cryogenics and chemical absorption are now also concentrating on membrane separations for specific market niches. Some examples of gas separation by membranes are shown in table 1.

Growth in the membrane gas separation has come about through a better understanding of the permeation process combined with the development of superior polymer materials and membranes.

\subsection{Sorption and permeation in glassy polymers}

It has been well-established that permeation of gases through membranes is a result of the sorption and diffusion of gases through polymers. The permeability $(P)$ of the

Table 1. Applications of membranes for gas separations.

\begin{tabular}{ll}
\hline Gases recovered & \multicolumn{1}{c}{ Applications } \\
\hline Oxygen/nitrogen & $\begin{array}{l}\text { Air enrichment for combustion } \\
\text { Inert gas for blanketing } \\
\text { Hydrocrackers } \\
\text { Hydrogen }\end{array}$ \\
& $\begin{array}{l}\text { Ammonia synthesis } \\
\text { Synthesis gas ratio adjustment } \\
\text { Acid gas treatment }\end{array}$ \\
Carbon dioxide & $\begin{array}{l}\text { Upgrading landfill gas } \\
\text { CO recycle in enhanced oil } \\
\text { recovery projects }\end{array}$ \\
Hydrogen sulphide & $\begin{array}{l}\text { Sour gas treating } \\
\text { Water vapour }\end{array}$ \\
Hydrocarbons & $\begin{array}{l}\text { Dehumidification } \\
\text { Pollution control }\end{array}$ \\
\hline
\end{tabular}


gas is given by

$$
P=D \cdot S
$$

where $D$ denotes the diffusivity, and $S$, the solubility of the gas in the polymer. Diffusion and sorption of gases depend on the nature of the polymer. As a result of the higher free volume, permeability of rubbery polymers to gases is usually higher than that of glassy polymers. However, rubbery polymers have comparatively low selectivities for most gas mixtures as they discriminate primarily on the basis of solubility differences. As a result, more attention is being focussed on glassy polymers as membrane materials for gas separation.

Sorption of gases in rubbery polymers follows Henry's law; whereas sorption of gases in glassy polymers is nonlinear with respect to pressure. The dual sorption model was proposed in the early seventies to explain the sorption of gases in glassy polymers (Vieth et al 1976). The net amount of gas sorbed was given by the equation:

$$
C=K_{D} p+C_{H}^{\prime} b p /(1+b p),
$$

where $C$ denotes the total concentration of the gas, $K_{D}$ denotes the Henry's law constant, $C_{H}^{\prime}$ denotes a microvoid sorption capacity and the affinity constant $b$ represents the ratio of the rate constants for sorption and desorption of the gas in the microvoid sites. This model postulates dissolution of the gas in accordance with Henry's law as well as adsorption in "microvoids". Originally the existence of a second sorption mode in glassy polymers was suggested only as a mathematical necessity for curve-fitting the observed nonlinear sorption isotherms. However, no non-controversial proof of this second sorption mode could be obtained though attempts were made using NMR (Assink 1975) and fluorescence measurements (Stern 1989). Even so, the model parameters were assigned physical significances, and in many cases, the values were consistent with the thermophysical characteristics of the polymers. However, several limitations became apparent. For instance, heats of sorption were inconsistent (Stern \& Kulkarni 1982), and $C_{H}^{\prime}$ did not correlate with the molar volume of the gas (Raucher \& Sefcik 1983). Also, in several cases, it has been necessary to postulate the pressure dependence of parameters $K_{D}(p), C_{H}^{\prime}$, (p) (Stern \& Saxena 1980). It can also be seen that the diffusion model for gas sorbed in these two sorption modes assumes either instantaneous equilibrium between the two modes or two parallel diffusion paths. To avoid this, a more complicated diffusion model was proposed (Sada et al 1988) in which interdiffusion between the gas populations was considered.

The most serious limitation, however, was that the presence of the two types of population of sorbed gases was not unequivocally established. Consequently, a gas-matrix interaction model, based on the assumption that the gas absorbed existed as a single population and that the presence of the gas modified the polymer structure, was proposed by Raucher \& Sefcik (1983). However, this approach did not offer any further insight into the nature of the interaction.

Experimental evidence is, however, building up to indicate that two (or more) sorption modes may in fact be operational in glassy polymers. The NMR work (Assink 1975) and the fluorescence experiments (Stern 1989) were mentioned above. Though the findings of these experiments were consistent with the two-sorption mode hypothesis, neither was definitive. In addition, the NMR work was carried out using $\mathrm{NH}_{3}$ dissolved in polystyrene in which the clustering tendency of the polar gas could not 
be ruled out. Recently, spin lattice and spin -spin relaxation spectra were investigated for ${ }^{13} \mathrm{CO}_{2}$ in polycarbonates (Cain et al 1991). The spin relaxation of ${ }^{13} \mathrm{CO}_{2}$ in polycarbonate could be interpreted in terms of a two-site exchange model, analogous to the dual-sorption model.

\subsection{Material selection considerations for membranes}

A recent report (Schwaar 1990) describes a large number of patents for newer polymers for gas separations. These belong to the family of modified polysulphones, polysiloxanes, substituted polyacetylenes, polyimides and fluorine-containing polymers.

In the selection of materials for membranes, four levels of membrane structures should be considered. These were first proposed by Hoehn \& Richter (1980) in connection with aromatic polyamide membranes. These levels consist of (1) the segmental structure of the polymer; (2) steric relationships in the segmental structure; (3) morphology of the membranes; and (4) morphology of the thin-film composite membranes. The first two levels relate to the chemical constitution of the polymer whereas the latter two relate to membrane properties which can be manipulated by the membrane-fabrication conditions. In this section, we will primarily discuss the material selection considerations based on the first two levels.

The ideal separation factor for the separation of the two gases $A$ and $B$ is given by

$$
\alpha=P_{\mathrm{A}} / P_{\mathrm{B}}=\left(S_{\mathrm{A}} / S_{\mathrm{B}}\right)\left(D_{\mathrm{A}} / D_{\mathrm{B}}\right),
$$

and can be considered to be the product of two selectivity factors, viz solubility selectivity and diffusivity selectivity. The values of the two parameters for a few polymers are summarized in table 2 . Clearly the key to develop polymers with high ideal separation factors lies in combining high solubility selectivity with high diffusivity selectivity. In addition, the polymer has to be highly resistant to the plasticizing activity of the penetrant gas so that selectivity is retained at high operating pressures.

A recurring problem with polymeric membranes has been the change in permeation properties with exposure to high pressure soluble gases. The permeation characteristics of glassy polymers with respect to pressure have been classified by Houde et al (1992) into four categories:

(1) $\mathrm{Tg}$ of the glassy polymer decreases below the temperature of the permeation experiment. The polymer then behaves like a typical rubbery polymer [e.g. poly(ethyl methacrylate)].

Table 2. Choice of polymers for $\mathrm{CO}_{2} /$ $\mathrm{CH}_{4}$ separation.

\begin{tabular}{llrl}
\hline Polymer* & $\mathrm{S}_{\mathrm{A}} / \mathrm{S}_{\mathrm{B}}$ & $\mathrm{D}_{\mathrm{A}} / \mathrm{D}_{\mathrm{B}}$ & $\mathrm{P}_{\mathrm{A}} / \mathrm{P}_{\mathrm{B}}$ \\
\hline PPO & 2.08 & 7.21 & 15.0 \\
PC & 3.6 & 6.81 & 24.4 \\
CA & 7.3 & 4.21 & 30.8 \\
PSF & 3.2 & 8.85 & 28.3 \\
PI & 4.1 & 15.38 & 63.6 \\
\hline
\end{tabular}

*PPO polyphenylene oxide; PC polycarbonate; CA cellulose acetate; PSF polysulphone; PI polyimide. 
(2) The polymer remains in the glassy state, but its permeability profile resembles that of a rubbery polymer [e.g. cellulose acetate (CA), poly(methyl methacrylate) (PMMA)].

(3) The permeability decreases with increasing pressure upto a critical pressure. Subsequent increase in pressure results in an increase in permeability (e.g. polycarbonates, polyimides).

(4) The permeability characteristics vary in accordance with the predictions of the dual sorption theory. However, the permeability is influenced by the exposure of the polymer to highly soluble gases such as $\mathrm{CO}_{2}$ at high pressures ("conditioning" effect).

Houde et al (1992) showed that wide angle X-ray diffraction (WAXD) measurements coupled with dynamic mechanical analyses (DMA) of the virgin and exposed polymer samples could be used to distinguish the mechanism of the plasticization/conditioning effect. This could be important in developing materials which are more resistant to plasticization.

Some of the newer materials that have been developed are reviewed below. None of these materials has yet been commercialized because of various unsolved problems. The promises and challenges of the material development efforts are summarized below.

\subsection{Substituted polycarbonates}

Hoehn \& Richter (1980) suggested that modifications of the polymer structure which resulted in increased interchain spacing combined with increased chain rigidity would result in increased permeability with little loss of selectivity. While this idea may be a considerable simplification, its application resulted in higher permeabilities and permselectivities in several classes of highly glassy polymers. This can be illustrated in a series of polycarbonates investigated by Hellums et al (1989). Substitution of the methyl groups on the bridge carbon in bisphenol-A polycarbonate by $\mathrm{CF}_{3}$ groups results in an increase in intersegmental chain spacing owing to the repulsion between polar $\mathrm{CF}_{3}$ groups. However, the rotational motion involving the monomer subunit and the carbonate linkage is not affected, as evidenced by the fact that the NMR correlation time $\left(T_{c}\right)$ remains the same. As a result, permeability to $\mathrm{CO}_{2}$ is increased substantially along with a moderate increase in permselectivity. On the other hand, substitution by methyl groups on the ring carbon atom, in addition to that by fluorine atoms at the bridge carbon atom, results in an increase in both intersegmental chain spacing and $T_{c}$. As a result, both permeability and permselectivity are enhanced significantly. Molecular motions in polycarbonates involve small-scale rocking motion of the repeat unit about the carbonate linkage. Hindrance in this motion is responsible for increase in permselectivity as well as permeability. However, these polymers are susceptible to plasticization, and this leads to a decrease in permselectivity with increasing partial pressure.

\subsection{Poly(1-trimethylsilyl-1-propyne)}

The permeability of poly(1-trimethylsilyl-1-propyne) (PMSP), a glassy polymer synthesized by Masuda et al (1983) was reported to be at least an order of magnitude higher than that of poly(dimethyl siloxane) (PDMS), the most permeable polymer known till then. Ichiraku et al (1987) found that the reason for the high permeability of PMSP was the high solubility particularly the high sorption capacity in the Langmuir 
mode [high value of $C_{H}$ in (2)]. The large frozen volume in PMSP may be due to its rigid main-chain structure owing to the presence of double bonds that are separated by bulky trimethylsilyl side-chains.

The decrease in the permeability of PMSP on aging has been a major limitation in its application as membrane material. This has been attributed to the collapse of frozen free volume with time. If the aging process in PMSP could be controlled, this polymer would have applications for low purity air separations, solvent/air separations etc.

\subsection{Facilitated transport}

Laciak et al (1990) recently reported the use of novel membranes, exploiting the concept of facilitated transport, for the separation of: (1) ammonia from nitrogen and hydrogen, and (2) carbon dioxide from hydrogen. The $\mathrm{CO}_{2}$ selective membrane was based on the reversible reactions between $\mathrm{CO}_{2}$ and molten TMAF $4 \mathrm{H}_{2} \mathrm{O}$. The bicarbonate and fluoride ions formed, diffuse to the permeate side where the reactions are reversed to generate $\mathrm{CO}_{2}$. At low partial pressures of $\mathrm{CO}_{2}$, the separation factor for the system $\mathrm{CO}_{2} / \mathrm{H}_{2}$ was as high as 370 . Both the permeability and the separation factor decreased with increasing partial pressure of $\mathrm{CO}_{2}$ as a result of the saturation of the carrier. Yet, it is significant to note that the separation factor is as high as 30 at a $\mathrm{CO}_{2}$ pressure of $80 \mathrm{~cm} \mathrm{Hg}$, in sharp contrast to conventional membranes in which the separation factor is 2 .

The ammonia-selective membranes were based on the reaction of $\mathrm{NH}_{3}$ with ammonium thiocyanate. $\mathrm{NH}_{3}$ has very high solubility in poly(vinyl ammonium thiocyanate) $\left(50 \mathrm{mmol} \mathrm{NH}_{3} / \mathrm{g}\right.$ polymer) at $600 \mathrm{~cm} \mathrm{Hg}$. Besides, the solubility curve does not indicate saturation at high pressures. The high solubility arises from the hydrogen-bonding interactions between $\mathrm{NH}_{3}, \mathrm{NH}_{4}^{+}$and $\mathrm{SCN}^{-}$ions, and is accompanied by a significant swelling of the polymer. As a result, the membrane selectively permeates $\mathrm{NH}_{3}$ from a mixture of $\mathrm{NH}_{3}$ and $\mathrm{H}_{2}$ or $\mathrm{N}_{2}$. However, since the solubility of $\mathrm{NH}_{3}$ decreases with increasing temperature, the separation factor decreases with increasing temperature. The mechanism of transport in such membranes has been illustrated by Bhown \& Cussler (1991).

One of the factors that has limited the development of air-separation technology is the low permeability and permselectivity. It was suggested that the facilitated transport of oxygen should help to overcome the barrier. Facilitated transport of oxygen and carbon dioxide through polymeric membranes containing specific additives has been reported in the past. Inorganic complexes used for the separation of oxygen, however, suffer from limited stability as a result of oxidation induced by the dimerization of metal complexes. In an effort to suppress the dimerization and thereby increase the stability of the complex, Nishide et al (1987) and Delaney et al (1990) have investigated polymeric membranes with grafted functional groups. However, the problems of stability and loss of selectivity at high pressures still have to be solved before the technique is commercially viable.

\subsection{Effects of membrane morphology}

For gas separation, apart from the selection of the polymer which governs the intrinsic separation and permeation characteristics of the membrane, tailoring of the membrane morphology is also very critical. The goal is to make a membrane with a very thin 
separating-layer or "skin" which has comparatively lower resistance to mass flow but the same selectivity as a thick film. This implies that an asymmetric membrane, with a separating layer $\approx 0.1 \mu \mathrm{m}$ thick, free from defects, pores etc., has to be made. This technique is used for the manufacture of gas-selective cellulose acetate membranes.

Recently, Fritzsche et al (1990) reported the synthesis of graded-density membranes in which the packing density varies across the thickness of the gel layer. The solvents used to cast these membranes formed Lewis acid-base complexes, e.g. propionic acid-N-methyl pyrrolidone. These complexes served as transient templates which could subsequently be broken down on extraction with water. The existence of the packing-density gradient across the thickness of the gel layer was demonstrated by an ingenious experiment in which the membrane skin was gradually etched by plasma ablation. There was a continuous decrease in the helium/nitrogen separation factor in the case of the graded-density membrane. In the case of the conventional asymmetric membranes, the separation factor remained constant until the dense skin was etched out and then decreased rapidly.

Liu \& Martin (1991) recently reported the development of a composite membrane containing a dense layer, $40 \mathrm{~nm}$ thick, formed by the photochemical polymerization of the monomer sorbed on the surface of a microporous support-membrane. The separation factor with $\mathrm{O}_{2} / \mathrm{N}_{2}$, with the composite membrane containing sulphonated polystyrene, was close to 8 , indicating that the separation essentially occurred by a diffusion-dissolution mechanism.

\section{Improved separations with porous membranes}

Ultrafiltration (UF) and microfiltration (MF) are pressure-driven membrane filtration processes with applications in the food, electronic, chemical and pharmaceutical industries. The primary mechanism of separation is usually size-exclusion by the porous membrane. In addition to the relative size of the solute with respect to the pore diameter, separation is also affected by other factors such as the interaction of the solute with the membrane material or the interaction of the solute with other feed components.

Most commercial UF/MF processes involve gross separations; the size ratio between the permeating and rejected species is 10 in commerical processes. Another drawback of UF/MF processes is the flux reduction as filtration proceeds. In spite of this, UF and MF are the most successful membrane operations in terms of total membrane sales and have the potential for much further growth. There are three general approaches to increasing their viability:

(1) Fabrication of more selective/membranes.

(2) Understanding of flux reduction and development of newer modules.

(3) Manipulation of feed chemistry.

\subsection{Membrane fabrication}

In order to discuss the fabrication of more selective membranes, it is necessary first to review briefly the mechanism of selectivity. There are several models of varying complexity which describe the selectivity mechanism of separation using porous UF/MF membranes. The simplest models only account for the relative size effect (Zeman \& Wales 1981), while more recent models also incorporate factors such as 


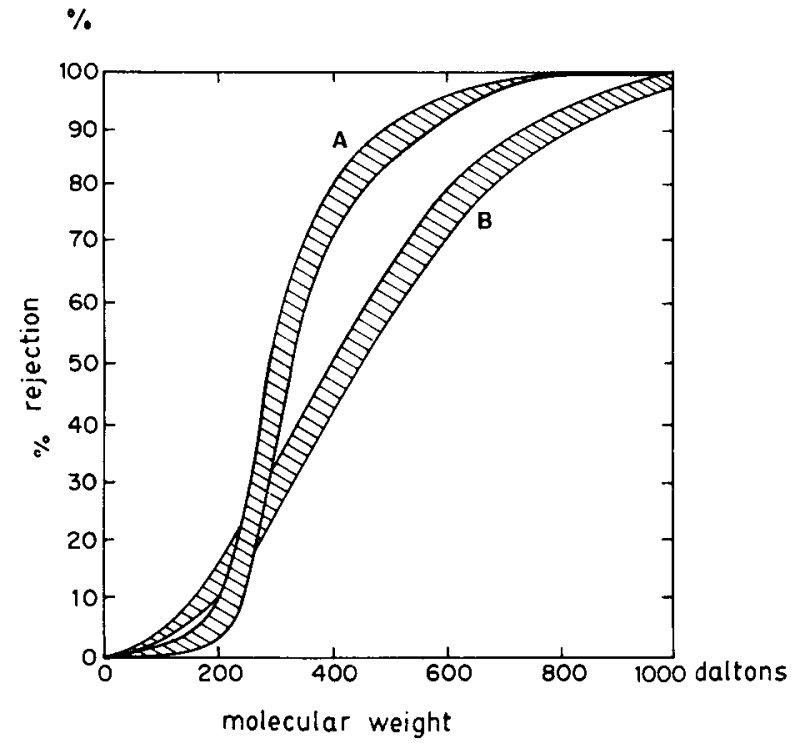

Figure 1. Molecular-weight cutoff (MWCO) profile for (A) hydrophilic membrane and (B) conventional polysulphone membrane.

solute distribution between fluid in the pores and in bulk solution, pore friction (Jonsson \& Boessen 1975; Matsuura \& Sourirajan 1981), heteroporosity (Zeman 1983) etc. The goal of these models is to describe the factors defining the sharpness of the selectivity profile. This so-called molecular-weight cut-off (MWCO) profile (see figure 1) is constructed by plotting the rejection of chemically similar solutes against their molecular weights. Cherkasov (1990) has proposed two parameters to define the MWCO profile; these are the average molecular-weight cut-off and, $\delta$, the dispersion coefficient of the rejection curve. The goal is therefore to make a membrane with the $\delta$ parameter as small as possible; for this the pores need to be of uniform size and distributed uniformly over the membrane surface. Most polymeric UF/MF membranes are made from solution casting by a "phase inversion" process; the surface of a typical membrane examined by scanning electron microscopy shows pores of various sizes scattered randomly over the surface. It appears improbable that pore uniformity can be significantly improved by the conventional casting route.

The first success in making membranes with uniform pore sizes was with the Nuclepore membranes, where nonporous polycarbonate is exposed to a collimated beam of $\alpha$-particles and then etched with $\mathrm{NaOH}$. This gives uniform, straight, through pores which are randomly distributed. There are a small number of larger pores caused by the merging of two nearby pores. Also, the thickness of these membranes is limited to the range of $10-20 \mu \mathrm{m}$.

A recent breakthrough by Sara et al (1988) has achieved the ultimate goal of uniform pores which are evenly distributed. These membranes are made from crystalline bacterial cell surface layers, deposited on a microporous substructure and then cross-linked using glutaraldehyde. The crystallinity of the layers leads to a uniform distribution of pores with equal diameters. By choosing different sources for these layers, the pore size can be changed, e.g. the surface layers from mesophilic eubacteria show $2-3 \mathrm{~nm}$ diameter channels and those from highly thermophilic eubacteria and archaebacteria possess larger channels ranging from 4-6nm. The channels lie in a porous lattice (20-50\% porosity) composed of the constituent proteins. These membranes give extremely sharp MWCO profiles. 
Neither the Nuclepore nor the bacterial cell layer membranes are as yet commercially feasible for large process applications. The phase inversion process by which many commercial membranes are made is considered as much an art as a science; however, several efforts have been made to study the membrane formation mechanism. In this process a polymer solution (in which the solvent forms a continuous phase) inverts to a polymer gel (continuous polymer phase) typically on exposure to a second miscible liquid which is a non-solvent for the polymer. Models to describe the process have been postulated; these models are either quantitative descriptions of the diffusion process (e.g. Yilmaz \& McHugh 1986) or qualitative descriptions based on the phase diagram for the ternary system of polymer, solvent and nonsolvent (e.g. Strathmann et al 1975). Techniques are being developed to measure the parameters required to use the models for predictive purposes (Ronner et al 1989). However, as mentioned before, the improvement in selectivity of membranes made by these conventional methods may be an incremental rather than a step-out change.

\subsection{Flux reduction: Importance of feed-membrane interphase}

The outstanding problem in UF/MF is the rapid flux reduction when the membrane is used to filter solutions of industrial importance. This phenomenon has negative connotations for both the flux through the membrane as well as its selectivity. In fact some recent theoretical work (Jonsson \& Johansen 1992) has shown that the diffuse MWCO seen in typical membranes is due not so much to their pore-size distribution as to the build-up of rejected components and membrane-solute interactions at the interface. Thus, this approach has a large potential for simultaneously increasing both membrane productivity as well as selectivity.

The basic physics of this phenomena was described very early by Blatt et al (1970). As solute is rejected by the membrane, its concentration builds up at the membrane surface so that the membrane is effectively separating, from the permeate, an actual concentration that is higher than the bulk concentration. This results in a lower observed rejection of the higher rejected species. This layer of rejected species also slows down those components which would otherwise freely pass through the membrane, thus increasing the rejection of the smaller species. The net result is a more diffuse MWCO profile and reduced flux. The phenomena of concentration polarization and fouling are especially critical for UF MF where the flux rates are high compared to other membrane processes.

Much innovative work has been done recently towards reducing concentration polarization with the goal of achieving at least the intrinsic membrane selectivity and flux.

3.2a Membrane chemistry. If the membrane surface is modified to reduce its attraction for rejected solutes, the sweeping cross-flow action will be better able to clean that surface. The type of sharper MWCO obtained by a novel, extremely hydrophilic UF membrane in comparison to that by a conventional type is shown in figure 1 . The modified membrane also shows less flux decline and needs to be cleaned less frequently. This approach is being followed by various membrane manufacturers.

3.2b Flow manipulation: Another promising approach is a combination of reversing, pulsating flow in a device where the membrane covers a series of porous, furrowed channels. Pulsatile flow causes vortices to be formed above and below the 
centre-flow line; when the flow direction is reversed, these vortices are ejected, carrying away the rejected solute. A six-fold increase in flux has been demonstrated by Jeffree et al (1981) for the UF of bovine whole blood.

In another novel device, membranes cover the annulus between two concentric cylinders through which the feed solution flows. On rotating the inner cylinder at a speed high enough to generate Taylor vortices as a result of flow instabilities, a cleaning mechanism is generated for sweeping away the rejected solutes. In an enzyme recovery process, this device gave higher fluxes as well as higher enzyme passage (Kroner \& Nissinen 1988).

It has been reported that low-frequency oscillations in the feed flow also give higher fluxes. This has been observed both in conventional modules as well as in the rotating concentric cylinder module (Vigo et al 1990).

None of these modules is as yet used on an industrial scale, though the rotating cylinder device has been scaled to pilot-plant level and has attracted a good deal of commercial attention. The disadvantages of these modules are their increased complexity (higher capital costs) and the fact that the additional turbulence which gives the superior cleaning action is at the cost of increased energy (pumping) imparted to the feed. Both costs and energy consumption of conventional membrane modules have decreased significantly which makes it all the more difficult for newer designs to achieve a market share. In spite of these drawbacks, the new modules have a large potential especially in laboratory and biotechnology applications.

3.2c Additional force fields: The basic idea is to use an additional force field to supplement feed flow or convection as a way of controlling concentration polarization. For example, if an appropriate potential gradient is established across the membrane, rejected (charged) species can be pulled away on the basis of their electrophoretic mobilities (Murlidhara \& Huffman 1988). Another device uses centrifugal force for the same objective. Yet another attractive idea is to use a conductive membrane as one electrode in order to establish the potential gradient. So far this has been tried with stainless steel membranes or by coating alumina-based ceramic membranes with conductive layers of either nickel or $\mathrm{RuO}_{2}-\mathrm{TiO}_{2}$ (Guizard et al 1989). It is expected that for highly fouling applications, the increased productivity would compensate for the additional energy cost and increased device complexity.

\subsection{Manipulation of feed chemistry}

If two species have sizes so close to each other that they cannot be separated easily, it may be possible to increase the size of one component artificially or to change its affinity for the membrane. This idea can be used in the fractionation of a proteincontaining solution in which changes in $\mathrm{pH}$ or electrolyte concentration can affect the polymer charge or conformation in solution and thereby change its rejection rate.

Several new techniques have been proposed in order to achieve separations that are not possible with porous membranes. One such method is micellar-enhanced ultrafiltration, in which a surfactant is added to the feed solution to a level exceeding the critical micellar concentration. For example, typical porous UF and MF membranes allow alcohols, phenols etc. to pass through as freely as water; hence, such membranes cannot be used to clean up waste water containing dissolved organics. However, when a surfactant is added, the organics occupy the hydrophobic core of the micelles formed. These micelles can be easily rejected by membranes which are not capable 
(a)

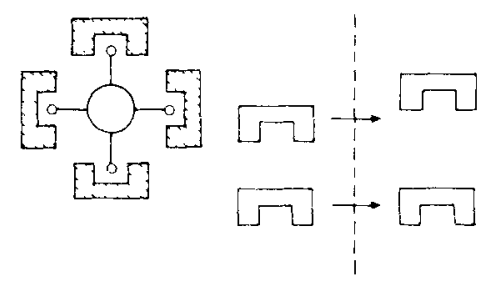

(b)

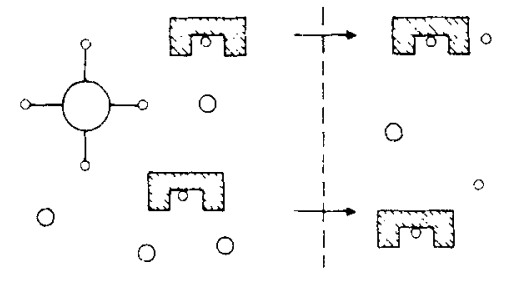

Figure 2. Separation of biologically active Concanavalin $\mathrm{A}$ (hatched) from inactive form using two sequential membrane processes: (a) washing step to separate inactive Con A from complexed active species, and (b) disassociation step to recover active Con A (adapteo from Matthiasson \& Ling 1986).

of rejecting the free organic molecules in solution (Gibbs et al 1987). This effect has also been used to increase the rejection of difficult-to-handle organics (e.g. urea) by reverse osmosis membranes (Swamikannu et al 1990).

The selection of surfactant determines the stability of the micelles, the distribution of the solute within the micelle and the bulk solution, and also the fraction of surfactant molecules dissolved in the bulk. Criteria for selecting surfactants have been discussed by Kandori \& Schechter (1990).

Chemical complexation is another way of very selectively increasing the size of one component from a mixture. A striking example is illustrated in figure 2 which schematically demonstrates the separation of biologically active Concanavalin A (Con A) from its inactive form (Matthiasson \& Ling 1986). Active Con A complexes with sugar residues on the surface of heat-treated Saccharomyces cerevisiae cells; the complex is then retained while the uncomplexed inactive form permeates through the membrane. A $0.5 \mathrm{M}$ glucose solution is then used to disassociate the active Con $\mathrm{A}$ which permeates the same membrane in a second step.

\section{Hybrid membrane processes}

Hybrid membrane processes can be interpreted in two ways. One interpretation involves a distinct membrane operation which is integrated with another unit operation(s), to give an integrated hybrid system. Examples of such hybrid processes (see figure 3 ) include the use of membranes to break the azeotropes in distillation columns (Pearce 1990), continuous removal of product and cell recycle fermenters (Flaschel \& Wandrey 1979), partial recovery of solvent in liquid extraction (Kulkarni et al 1986), bulk removal of acid gas before amine scrubbing (Kulkarni et al 1983) etc. The membrane fulfils only one particular function in the integrated process. The overall integrated process takes advantage of the capabilities of each unit operation. Such hybrid systems are likely to become increasingly important as the capabilities of membrane systems become better established and known. Much process research and development is still required to define the overall optimal configuration in any particular application. 


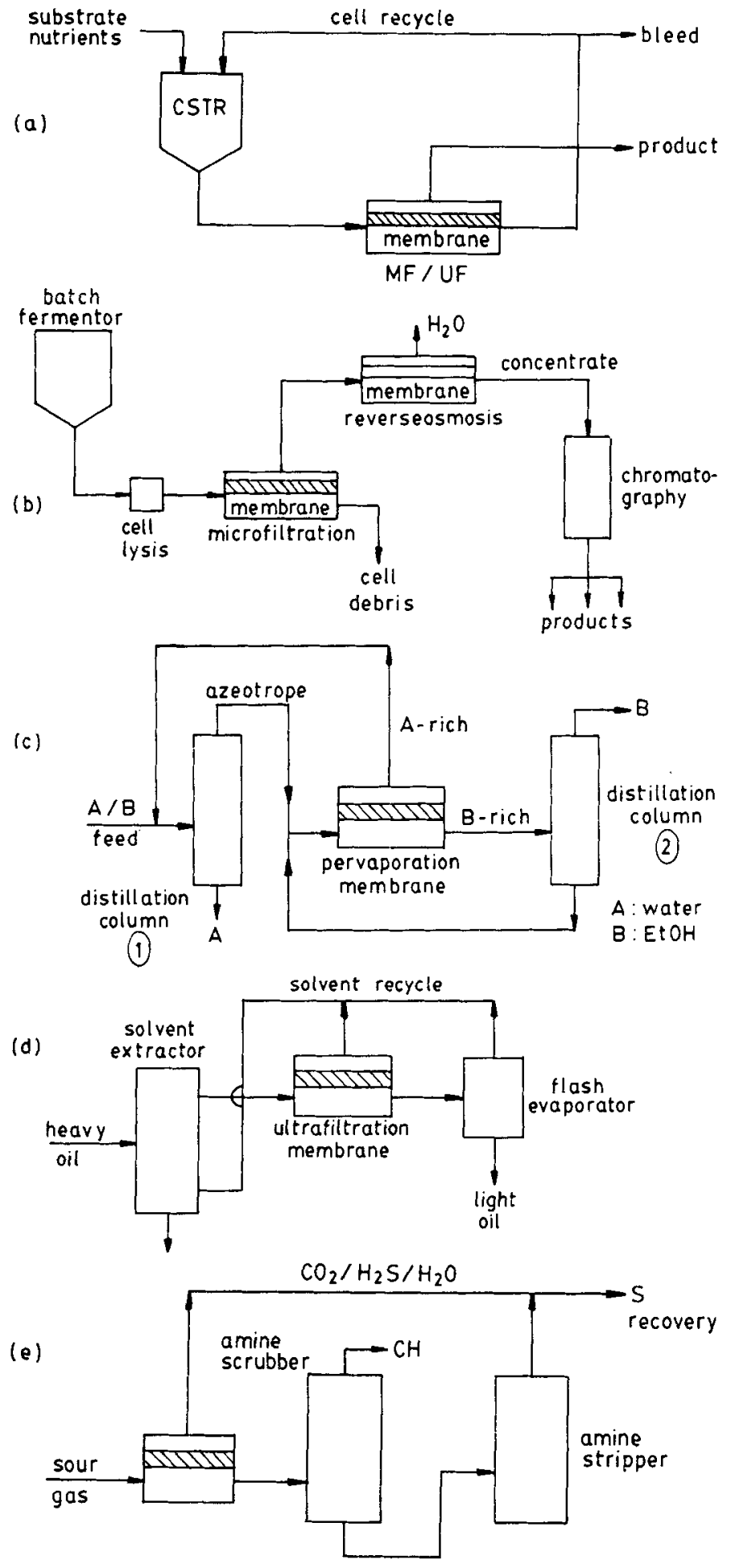

Figure 3. Examples of hybrid integrated membrane processes: (a) Cell recycle by microfiltration membrane attached to continuous fermentor with continuous removal of clarified brothcontaining product; (b) Purification train for product from batch fermentor cell: debris is removed by ultrafiltration and concentrated by reverse osmosis before chromatographic purification; (c) Azeotrope-breaking by a pervaporation membrane in alcohol-water distillation; (d) Partial recycle solvent using an ultrafiltration membrane; (e) Bulk removal of acid gases $\left(\mathrm{CO}_{2}, \mathrm{H}_{2} \mathrm{~S}\right.$, moisture) before final purification of natural gas by amine scrubbing. 
In another interpretation, the membrane is coupled with a second physical or chemical operation apart from separation. In such hybrid processes the membrane is still necessary as a phase separator with high interfacial area/device volume, but the role of the membrane may be changed from being the primary separator to providing a suitable medium for the real transfer-agents. Examples of hybrid processes according to this second interpretation are discussed below.

\subsection{Membrane chromatography}

In conventional protein chromatography the ideal adsorbent column is a short, wide column consisting of small (micron-sized) adsorbent beads. This requirement is because of the relatively low mobility of proteins coupled with the development of extremely selective adsorbents (affinity chromatography). This shape requirement is met ideally by membrane films (short plus wide column of small beads $=$ thin plus large area membrane with small pores). On grafting suitable ligands, monoclonal antibodies, hydrophobic groups etc. on the membrane surface and pore walls, the appropriate chromatography can be performed. By using different solvents (or varying $\mathrm{pH}$ ), solutes may be fractionated in addition to being recovered in a concentrated form. The major drawback of this concept is that the number of stages is limited. Hence, this method is appropriate only when adsorption is inherently efficient. The advantages are that low feed pressures can be used compared to conventional chromatography (Svec 1991. pp. 671-4) and the equipment used is compact (Zale et al 1990, pp. 160-2).

\subsection{Membrane reactors/extractors}

Membranes in different modular forms have been used as reactors or as contacting devices in liquid-liquid extraction. The advantages of membrane devices in these applications lie mainly in their very high surface area to volume ratios. (typically $10^{3} \mathrm{~m}^{2} / \mathrm{m}^{3}$ in hollow fibre modules). In addition, it is possible to get selective transport of reactants/products by choosing membranes of appropriate materials, pore sizes etc.; this can be used to change the reaction equilibrium. In liquid-liquid processing the ability to bring two phases in intimate contact without emulsion formation could be critical. Membrane devices are often compact in size, are available in modular forms and are easy to scale up. Their higher cost can be offset by the advantage of faster reaction or transfer rates and improved efficiency of conversion.

The use of polymeric membranes in general chemical reactions has been greatly limited by their inadequate temperature and chemical resistance. By comparison, this problem does not exist in the case of inorganic membranes. Alumina-based membranes have been studied in reference to reactions such as the decomposition of $\mathrm{H}_{2} \mathrm{~S}$ to $\mathrm{H}_{2}$ and S (Kameyama et al 1981; Abe 1987), conversion of sucrose to glucose (Nakajima et al 1987), dehydrogenation of cyclohexane (Shinji et al 1982) etc.

Polymeric membrane reactors have had a tremendous impact on biotechnology, particularly for the production of small quantities of high value products. Hollow fibre reactors have been by far the most popular module configuration used. The biocatalyst may be present either within the membrane itself or outside it, i.e. in the extracapillary space (ECS) around the fibres or within the bore of the hollow fibre.

An example of a biotransformation carried out in the ECS of a hollow fibre bioreactor is the growth of microbial, viral, animal or plant cells (tissue culture) 
(Belfort 1989). Very high cell loadings (upto $10^{12} \mathrm{cells} / \mathrm{ml}$ ) have been achieved by this method (Vick Roy et al 1983). After growth, manipulation of the nature of the feed can be used to produce secondary metabolites like monoclonal antibodies (Calabresi et al 1981), plant pigments (Jose et al 1983, pp. 409-12) etc. The advantages of carrying these operations in the hollow fibre module are primarily that sterility can be ensured by supplying nutrients through the membrane, very high cell loadings are possible, low molecular weight products can be continuously removed, and cells do not experience shear forces. A major problem is the mass transfer resistance encountered in supplying adequate nutrients and especially oxygen required by the large cell mass. Robertson \& Kim (1985) have suggested a possible solution in the use of dual hollow fibre reactors where nutrients are supplied through microporous polypropylene hollow fibres and gases through an outer silicone tubular membrane. Each silicone tube contains several of the polypropylene hollow fibres.

Another bioreaction carried out in hollow fibre modules is a process operated by Degussa (Konstanz, Germany) producing 5 tonnes of L-amino acids (methionine, alanine, phenylalanine and valine) per month (Schmidt-Kastener \& Egerer 1984). The L-amino acids are produced from racemic mixtures using an acylase enzyme that selectively cleaves the L-acetyl derivative to give the corresponding L-amino acid, which is then isolated by crystallization.

Several reactions have been carried out with the biocatalyst physically entrapped in the membrane pores. This has been used for the separation of racemic mixtures by entrapping an acylase in the pores of a membrane separating an organic phase containing the feed racemic solution from an aqueous phase (Sepracor Inc. 1987). For example, the enzymatic resolution of N-benzyl-D, L-tyrosine ethyl ester is accomplished by selectively hydrolyzing the L-ester; the acid is then extracted by the aqueous phase while the D-ester remains in the organic phase. A similar scheme was used for the resolution of the beta-blocker intermediate, glycidol, produced from a racemic mixture of the corresponding butyrate esters. Enzymes/cells have also been entrapped during the actual membrane casting; galactosidase has been entrapped in a hollow fibre membrane made from a dope consisting of polysulphone, polyvinyl pyrollidone and dimethyl acetamide (Drioli 1986).

\subsection{Carrier-mediated transport}

Carrier-mediated or -facilitated transport can actually be included in the previous scheme incorporating membrane separation with a reaction mechanism. However, because of the potential for very high and selective separation that is possible with this method, it is discussed below separately.

Carrier-mediated transport is a common feature in biological membranes, which far outclass synthetic membranes in terms of transport efficiency (moles permeated/ driving force) and selectivity. One possible mechanism is that there is a mobile carrier in the membrane phase which selectively complexes the desired molecule; the complex diffuses to the membrane interface with the stripping solution, from where after disassociation and release of the penetrant, the carrier molecule diffuses back to the membrane interface with the feed solution. For example, if the chelating agent, LIX 64, is dissolved in an organic phase imbibed in the membrane pores, this can be used to transport $\mathrm{Cu}^{++}$from metal-finishing waste-water material into a second smaller stripping aqueous phase ( $\mathrm{Li}$ et al 1983). There are many variations in the basic principle also including "uphill" transport, i.e. transport against the nominal concen- 
EMULSION LIQUID MEMBRANE

(a)
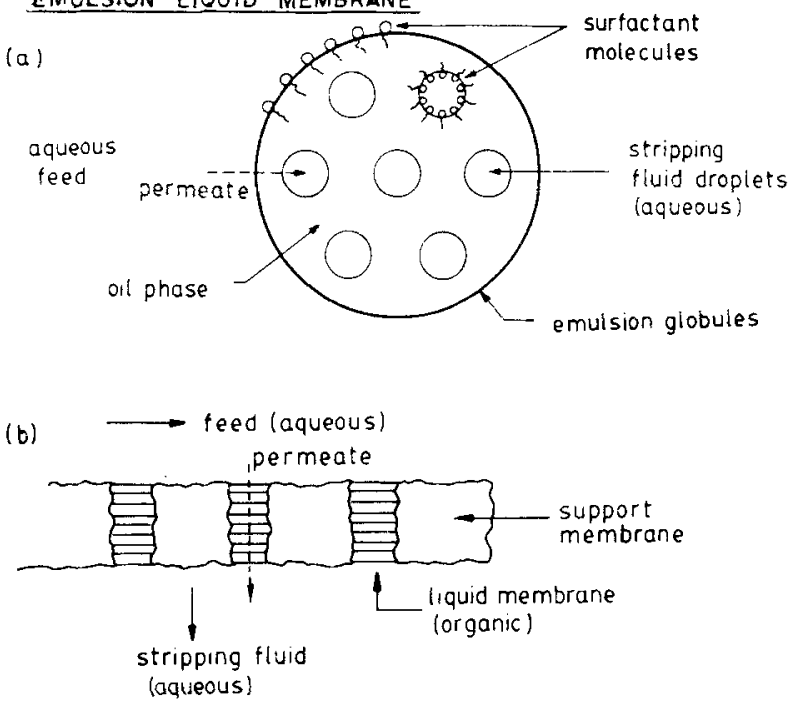

(c)

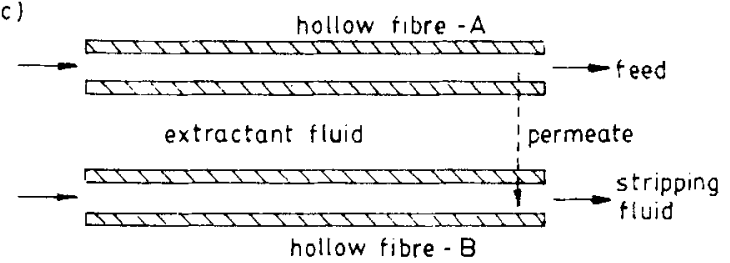

Figure 4. Three types of liquid membranes: (a) emulsion, (b) immobilized and (c) contained (see text for details).

rration gradient. Uphill transport is achieved by a suitable chemical reaction to trap the transported species in the stripping phase.

Carrier-mediated transport usually takes place in "liquid" membranes consisting of an immiscible liquid barrier between two liquid or gas phases. Liquid membranes can be prepared in two main configurations. When liquid containing a complexing agent is entrapped within the pores of a porous membrane, it gives an immobilized (or supported) liquid membrane (ILM) (e.g. Noble \& Way 1987). When an emulsion of two immiscible phases, after formation, is subsequently dispersed in a third continuous phase, an emulsion liquid membrane (ELM) is formed ( $\mathrm{Li} \mathrm{1968)} \mathrm{(see}$ figure 4). The use of liquid membranes is particularly attractive for those reactions/ separations whose rates are diffusion-controlled. This is on account of the large interfacial areas between dispersed and continuous phases and the much higher diffusion coefficients that prevail in liquids than in solids.

Immobilized liquid membranes have received considerable attention for hydrometallurgical applications like recovery of copper using a beta hydroxyoxime carrier (Baker et al 1977) and for the recovery of products of fermentation such as citric acid and acetic acid (Kuo \& Gregor 1983). Other potential uses are in the manufacture of ion selective electrodes (Bard \& Faulkner 1980) and gas sensors selective for organic vapours (Deitz 1989). Emulsion liquid membranes have been investigated for the separation of metal ions like zinc, uranium and copper ( $\mathrm{Li}$ et al 1983), and also for the recovery of amino acids (Makryaleas et al 1985; Thun et al 1986) and drugs like codeine.

The commercial exploitation of liquid membranes has been hampered by several factors. The two major problems associated with immobilized membranes are loss 
of the membrane-solvent phase through evaporation or emulsification and loss or deactivation of the carrier species. In order to minimise evaporation, feed- and stripping-gases may be pre-saturated with solvent. Ion-exchange membranes have also been used as supports for the ILM; the concept is to prevent membrane loss by augmenting the restraining capillary forces with polar interactions. A major problem with emulsion membranes appears to be the emulsion forming/breaking process. A new concept here is the electrostatic pseudo-liquid membrane (Gu 1990).

In spite of potential probiems, liquid membranes are still attractive because of the amazing selectivities possible. To give just one example, Izatt et al (1989) report cation selectivities in an ILM composed of a crown ether (bis(1-hydroxyheptyl cyclo hexano)-18-crown-6) in phenylhexane. The selectivity for $\mathrm{K}^{+}$over $\mathrm{Na}^{+}$(nitrate salts) is reported to be $86: 1$.

A new concept which overcomes the stability problem of the liquid membrane phase is that of contained liquid membranes (figure 4c) (Prasad \& Sirkar 1987). Feed and stripping phases flow through alternate hollow fibres in the same module. Permeate is transferred between these two phases through the liquid-membrane phase contained in the shell by two sequential liquid-liquid extraction steps. This basic idea and its modifications have aroused much interest and are being actively studied.

Carrier-mediated transport in solid membranes has also been demonstrated. The mechanism of such transport has not been clearly established. Cussler et al (1989) have proposed a mechanism in which the solute forms complexes with carrier molecules which have limited mobility but are close to each other. This mechanism has been likened to Tarzan (solute) swinging through the vines (carriers) in a jungle (membrane). In contrast, a second mechanism proposed by Noble (1990) has been likened to bacteria (solute) migrating from colony to colony (carrier) on a plate (membrane). Unlike the first mechanism, this does not postulate a minimum carrier concentration above which carrier effects on steady-state transport can be observed. Definitive experiments to establish the requirement of a minimum carrier concentration are yet to be done.

\subsection{Other membrane hybrids}

The possibilities of useful separation by coupling two different separation principles are numerous and cannot all be covered here. Several notable applications are the use of membranes in liquid-liquid extraction (to prevent emulsification), in electrophoresis, and in electrochemical processing, e.g. fuel cells or bipolar membranes.

\section{Concluding remarks}

We have reviewed recent advances and avenues for further research and development in three specific fields of membrane science and technology. The selection of these three fields is arbitrary; however, we do believe that these areas will become increasingly important.

\subsection{Gas separation by membranes}

This field has the potential for rapid growth. While a considerable amount of work has been done on the fundamental mechanism of gas transport, there are still several 
anomalies and controversies with respect to the dual-sorption theory. Working correlations are being developed between polymer structure and permeation characteristics. New improved materials which combine both high permeability and selectivity have been designed using the thumb-rule of combining an open polymer network with high chain rigidity. Molecular modelling techniques may also be used to develop and understand other improved materials and to tailor selectivities. The area of membrane fabrication is also an important area for future research.

\subsection{Improving the separation characteristics of porous membranes (ultrafiltration/ microfiltration)}

Three approaches for improved separations using porous membranes have been discussed. Membranes with uniform pore sizęs and distributions have been recently synthesized. The task is now to achieve the same goal using methods more amenable to production for large commercial applications. The role of the feed-membrane interface is also critical. New membrane materials and new module/process configurations have been developed to increase separation efficiency. Manipulation of feed chemistry via addition of surfactant, complexation etc. is also a method for achieving selective separations which are not otherwise possible at all using porous membranes. The improvement of membrane separations by these methods will greatly increase the viability of ultra- and microfiltration processes.

\subsection{Hybrid membrane processes}

Hybrid membrane processes can be considered as (i) integrated membrane processes or (ii) coupled transport processes. Integrated processes will become increasingly common; these use membranes in one unit operation in conjunction with other unit operations, e.g. distillation, fermentation etc. In coupled transport processes, the role of the membrane is intimately coupled with another physical/chemical process such as chromatography, reaction etc. The use of membranes as bio-reactors is a fruitful area of $R$ \& D. Carrier-mediated transport has not achieved major commercial status but still has alluring possibilities. This type of transport has been studied in various liquid membranes (immobilized, emulsion, and contained types) and has also been demonstrated in solid polymer systems. A good deal of basic research is still needed in this area.

\section{References}

Assink R A 1975 Investigation of the dual mode sorption of ammonia in polystyrene by NMR. J. Polym. Sci. Polym. Phys. Ed. 13: 1665-1673

Baker R, Tuttle M, Kelly D, Lonsdale H 1977 Coupled transport membranes. J. Membr. Sci. 2: $213-233$

Bard A, Faulkner L 1989 in Electrochemical methods (New York: J Wiley \& Sons)

Belfort G 1989 Membrane and bioreactors: A technical challenge in biotechnology. Biotechnol. Bioeng. 33: 1047-1066

Bhown A, Cussler E 1991 Mechanism for selective ammonia transport through poly(vinyl ammonium thiocyanate) membranes. J. Am. Chem. Soc. 113: 742-749

Blatt W F, Dravid A, Michaels A S, Nelsen L 1970 in Membrane Science and Technology (ed.) J E Flynn (New York: Plenum)

Business Technology Report 1986 cited in Polymer News (1989) 12(7): 215 
Cain E J, Wen W Y, Jones A A, Inglefield P T, Cauley B J, Bendler J T 1991 A dual mode interpretation of spin relaxation of ${ }^{13} \mathrm{C}$ carbon dioxide sorbed in polycarbonate. J. Polym. Sci., Polym. Phys. Ed. 29: 1009-1020

Calabresi P, McCarthy K, Dexter D, Cummings F, Rotman B 1981 Proc. Am. Assoc. Cancer Res. 22: 302-306

Cherkasov N 1990 Selective ultrafiltration. J. Membr. Sci. 50: 109-130

Cussler E L, Aris R, Bhown A 1989 On the limits of facilitated diffusion. J. Membr. Sci. 43: $149-164$

Deitz D 1989 Proc. IVth Int. Conf. Indoor Air Qual. and Climate (Berlin)

Delaney M S, Reddy D, Weissling R A 1990 Oxygen/nitrogen transport in glassy polymers with oxygen binding pendent groups. J. Membr. Sci. 49: 15-36

Drioli $E 1986$ Membrane processes in the separation, purification and concentration of bioactive compounds from fermentation broths. ACS Symp. Ser. 314 (5): 52-66

Flaschel E, Wandrey C 1979 Membrane reactors. Dechema Monogr. 84: 337-366

Fritzsche A K, Murphy M K, Kesting R E 1990 Polysulfone hollow fiber membranes spun Lewis acids and base. J. Appl. Polym. Sci. 39: 1949-1956

Gibbs L L, Scamehorn J F, Christian S D 1987 Removal of n-alcohol from aqueous streams using micellar enhanced ultrafiltration. J. Membr. Sci. 30: 67-74

Gu Z M 1990 A new liquid membrane technology-electrostatic pseudo liquid membrane. $J$. Membr. Sci. 52: 77-88

Guizard C, Legault F, Idrissi N, Larbot A, Cot L, Gavach C 1989 Electronically conductive mineral membranes designed for electro ultrafiltration. J. Membr. Sci. 41: 127-142

Hellums M W, Koros W J, Husk G R, Paul D R 1989 Fluorinated polycarbonates for gas separation application. J. Membr. Sci. 46(1): 93-112

Hoehn H H, Richter J W 1980 Aromatic polyimide, polyester and polyamide separation membranes. US Patent Reissue 30,351

Houde A Y, Kulkarni S S, Kulkarni M G 1992 Permeation and plasticization behaviour in glassy polymers: A WAXD interpretation. J. Membr. Sci. 71: 117-128

Ichiraku Y, Stern S A, Nakagawa T 1987 An investigation of the high permeability of poly(1-trimethylsilyl-1-propyne). J. Membr. Sci. 34: 5-18

Izatt R M, Roper D K, Bruening R L, Lamb J D 1989 Macrocycle mediated cation transport using hollow fiber supported liquid membranes. J. Membr. Sci. 45: 73-84

Jeffree M A, Peacock J A, Sobey I J, Bellhouse B J 1981 Gel layer limited hemofiltration rates can be increased by vortex mixing. Clin. Expt. Dialysis Apheresis 5: 373

Jonsson G, Boessen C E 1975 Water and solute transport through cellulose acetate reverse osmosis membranes. Eesalination 17: 145-165

Jonsson G, Johansen P L 1992 Selectivity of ultrafiltration membranes: Influence of fouling and cleaning conditions. Proc. Indo-EEC Workshop (New Delhi: Dept. Sci. Technol.) p. $145-184$

Jose W, Pedersen H, Chin C 1983 Sucrose hydrolysis and phenolics production by Daucus canota entrapped in hollow fiber reactor. Biochemical Engineering (New York: New York Acad. Sci.) vol. 3

Kameyama T, Dokiya M, Fiyishige M, Yokokawa H, Fukuda K 1981 Possibility of effective production of $\mathrm{H}_{2}$ from $\mathrm{H}_{2} \mathrm{~S}$ by means of a porous Vycor glass membrane. Ind. Eng. Chem. 20: 97-99

Kandori K, Schechter R S 1990 Selection of surfactants for micellar enhanced UF. Sep. Sci. Technol. 25: 83-108

Kulkarni S S, Funk E W, Li N N 1986 Hydrocarbon separations with polymeric membranes. AlChE Symp. Ser. 250(82): 78-84

Kulkarni S S, Funk E W, Li N N, Riley R 1983 Membrane separation processes for acid gases. AIChE Symp. Ser. Electrochem. Eng. 1I: 172-178

Kroner K, Nissinen V 1988 Dynamic filtration of microbial suspensions using an axially rotating filter. J. Membr. Sci. 36: 85-100

Kuo Y, Gregor H 1983 Acetic acid extraction by solvent membrane. Sep. Sci. Technol. 18: $421-440$

Laciak D V, Quinn R, Pez G P, Appleby J B, Puri P S 1990 Selective permeation of ammonia and carbon dioxide by novel membranes. Sep. Sci. Technol. 25: 1295-1305

Li N N 1968 Separating hydrocarbons with liquid membranes. US Patent 3410794 
Li N N, Cahn R P, Naden D, Lai R W M 1983 Liquid membrane processes for copper extraction. Hydrometallurgy 9: 277-305

Liu C, Martin C R 1991 Composite membranes from photochemical synthesis of ultrathin polymer films. Nature (London) 352: 50-52

Makryaleas K, Scheper T, Schugel K, Kula M 1985 Enzyme catalysed preparation of L-amino acids with continuous coenzyme regeneration by using liquid membrane emulsions Chem.-Ing.-Tech. 57: 362-363

Masuda T, Isobe E, Higashimura T 1983 Poly(1-(trimethyl silyl)1-propyne): A new high polymer synthesised with transition metal catalyst and characterized by extremely high gas permeability. J. Am. Chem. Soc. 105: 7473-7474

Matsuura T, Sourirajan S 1981 Reverse osmosis transport through capillary pores under the influence of surface forces. Ind. Eng. Chem., Process Des. Dev. 20: 273-282

Matthiasson B, Ling T G I 1986 in Membrane separation in biotechnology (ed.) W C McGregor (New York: Marcell Dekker)

Murlidhara H S, Huffman W S 1988 Proc. 6th Annu. Membr. Technol./Planning Conf. (Cambridge, MA)

Nakajima M, Jimbo N, Nishizawa K, Nabetaani H, Watanabe A, Nakao S 1987 Proc. Int. Congress Membrane Processes, Tokyo, Japan

Nishide H, Ohyanogi M O, Okada O I, Tsuchida E 1987 Dual mode transport of molecular oxygen in a membrane containing cobalt porphyrin complex as a fixed carrier. Macromolecules 20: 417-422

Noble R D 1990 Analysis of facilitated transport with fixed site carrier membranes. J. Membr. Sci. 50: 207-214

Noble R, Way J D 1987 Liquid membranes: Theory and applications. ACS Symp. Ser. 347: 1-26

Pearce G K 1990 Hybrid pervaporation/distillation processes for alcohol dewatering. Proc. Int. Conf. Membr. (Chicago, IL)

Prasad R, Sirkar K K 1987 Solvent extraction with microporous hydrophilic and composite membranes. AlChE J. 33: 1057-1066

Raucher D, Sefcik M 1983 Gas transport and cooperative main chain motions in glassy polymers. ACS Symp. Ser. 233: 89-110

Robertson C R, Kim I L 1985 Dual aerobic hollow fiber bioreactor for cultivation of Streptomyces aureofaciens. Biotechnol. Bioeng. 27: 1012-1020

Ronner J A, Groot-Wassink S, Smolders A 1989 Investigation of liquid-liquid demixing and aggregate formation in a membrane forming system by means of pulse induced critical scattering. J. Membr. Sci. 42: 27 45

Sada E, Kumazawa H, Xu P and Mishigaki M 1988 Mechanism of gas permeation through glassy polymer films. J. Membr. Sci. 37: 165-179

Sara M, Manigley C, Wolf G, Sleytr U B 1988 Isoporous ultrafiltration membranes from bacterial cell envelope layers. J. Membr. Sci. 36: 179-186

Schmidt-Kastener G, Egerer P 1984 in Biotechnology (ed.) K Kieslich (Berlin: Springer Verlag) 6A: 412

Schwaar R H 1990 Membranes for gas separation. Proc. Economics Progress, SRI Int Report No. 90

Sepracor Inc 1987 Company Brochure, Marlborough, MA

Shinji O, Misono M, Yoneda Y 1982 The dehydrogenation of cyclohexane by use of a porous glass reactor. Bull. Chem. Soc. Jpn. 55: 2760-2764

Stern S A 1989 Evidence of dual mode diffusion of small molecules in glassy poly(1-trimethyl silyl-1-propyne) from fluorescence photobleaching recovery. J. Polym. Sci. C27: 427-431

Stern S A, Kulkarni S S 1982 Solubility of methane in cellulose acetate conditioning effect of carbon dioxide. J. Membr. Sci. 10: 235-251

Stern S A, Saxena V 1980 Concentration dependent transport of gases and vapours in glassy polymers. J. Membr. Sci. 7: 47-59

Strathmann H, Kock K. Amar P, Baker R W 1975 Formation mechanism of asymmetric membranes. Desalination 16: 179-203

Svec F 1991 Polymeric separation media for chromatography in an innovative shape: membranes. In Polymer science contemporary themes (ed.) S Sivaram (New Delhi: Tata-McGraw Hill) vol. 2

Swamikannu A X, Funk E W, Li N N, Kulkarni S S 1990 Recovery of space station washwater by membrane technology. Proc. Int. Conf. Memb. (Chicago, IL) 
Thun M, Hatton A, Wang D I C 1986 Liquid emulsion membranes and their applications in biochemical separations. ACS Symp. Ser. 314(6): 67-77

Vick Roy T, Blanch H, Wilke C 1983 Microbial hollow fiber reactors. Trends Biotechnol. 1: 135-139

Vieth W R, Howell J M, Hseih J H 1976 Dual sorption theory. J. Membr. Sci. 1: 177-220

Vigo F, Uliana C, Ravina E 1990 The vibrating ultrafiltration module performance in the low frequency region. Sep. Sci. Technol. 25: 63-82

Yilmaz L, McHugh A J 1986 Analysis of nonsolvent-solvent polymer phase diagrams and their relevance to membrane formation modeling. J. Appl. Polym. Sci. 31: 997-1018

Zale S E, O'Connor J L, Matson S L 1990 Hollow fiber affinity membrane separations in downstream processing. Proc. Int. Conf. Membr. (Chicago, IL)

Zeman L 1983 Adsorption effects in rejection of macromolecules by ultrafiltration membranes. J. Membr. Sci. 15: 213-230

Zeman L, Wales M 1981 Polymer solute rejection by ultrafiltration membranes. ACS Symp. Ser. 154: 412-434 